\title{
IMPACT OF ECONOMIC INDICATORS ON DEVELOPMENT OF CAPITAL MARKET
}

\author{
Rudolf Plachý, Tomáš Rašovec
}

\section{Introduction}

Capital market is one of the most important elements of any healthy, well-functioning economy. The volume and value of executed capital market transactions are affected not only by the number of issuers and investors' willingness to buy, but also by economic development in the broadest sense.

Evaluation of current and particularly future development of financial instruments can be approached from various perspectives. Most authors distinguish fundamental, technical and psychological analysis [24], [13]. Fundamental analysis can be performed at three levels. Veselá [24] describes global, industry and company fundamental analysis. The main objective of global fundamental analysis is identification, exploration and evaluation of the impact of the whole economy on the market value of analyzed shares. For description of status and development of economies and markets one can use important global macroeconomic aggregates, factors and variables, such as interest rates, inflation, GDP, money supply, movement of international capital and movements in exchange rates, political and economic shocks, etc.

Jilek [13] states that the long-term trend in stock prices reflects, among others, trends in macroeconomic variables such as GDP, employment, inflation, business cycle, money supply, exchange rate, government spending, balance of payments, political factors. The author also highlights the various schools of thought. Very interesting is "efficient market hypothesis" of Eugene Fama, according to which no one can beat the market. However, for example Meriwerther group in Salomon Brothers managed to find inefficiencies.

In this paper the effect of macroeconomic indicators on development of stock indices of twenty selected countries is investigated.

\section{Objective}

A fractional objective of this paper is identification of economic indicators which significantly directly or indirectly affect the values of stock indices of individual countries. This selection was undertaken pursuant to a particular economic theory and logical interpretation of the influence of individual parameters on the development of a stock market index. The main objective of this work is to compare these dependencies between selected indicators and equity indices value within states and subsequent classification of countries into homogeneous groups based on the observed strengths of partial dependencies.

\section{Literature Review}

There is a great number of authors discussing the issue of stock market development prediction and analyzing relationships between macroeconomic indicators and stock market. Even though individual authors use different methods, their approaches often have common features. These are focus on a specific market and consecutive determination of factors with the greatest influence on the local stock market development.

In the past most studies focused mainly on the relationship between stock prices and macroeconomic indicators in developed industrial countries, such as the U.S. ([4], [6]), Japan [16] or Italy [18]. For example Bulmash and Trivoli [4] found that stock market in the U.S. has a very strong relationship with interest rates, both short-term and long-term. Other studies [1] revealed that stock market is influenced, among others, by inflation, trade deficits and interest rates. Kim [14] examined the relationship between macroeconomic indicators and value of US S\&P 500 index. He found that there is a positive relationship with 
industrial production and negative relationship with interest rate. Recently researchers have started to pay attention to this particular topic even in developing countries, for example Oskenbayev et al [17], Pilinkus and Boguslauskas [19] and others.

Oskenbayev et al. [17] focused on the Kazakh market. Through tests in a framework of the Autoregressive Distributed Lag model the authors reached a conclusion that the local stock market index is particularly affected by income per capita, inflation, interest rate, and a dummy variable which presented the world crisis influence. Pilinkus and Boguslauskas [19] analyzed relationships between the stock market and macroeconomic indicators in Lithuania. Impulse response function was used to test for existence of relationships between the stock market index and short-run macroeconomic indicators. Their results showed a positive influence of gross domestic product and money supply and a negative influence of unemployment rate, exchange rate and shortrun interest rate on stock market returns.

Snieska et al. [23] deal with the relationships between the Lithuanian stock market and macroeconomic indicators of the country. They examine the influence of macroeconomic factors on the dynamic of the stock index by using regression and correlation analyses. The results of their research show a fairly strong relationship between individual indicators and stock market.

Goh et al. [8] assume that in a globalized world a stock market of one country can be affected also by macroeconomic indicators of another country. Results show that China's joining the World Trade Organization at the end of 2001 caused an increase of the influence of US macroeconomic indicators on the Chinese stock market. Kralik [15] focused on the influence of local and global factors on stock market development in Romania with usage of a macroeconomic APT model. His analysis confirmed an effect of exchange rates, global interest rates, gold price, global stock market indices and crude oil price on stock market index development in Bucharest.

\section{Methodology}

The basic methodological tools for solution of the problems discussed in this study were correlation analysis and multivariate statistical methods of factor and cluster analysis. All calculations were performed in the statistical software SPSS 19.

\section{Data}

Data matrix compilation was a very important task. Methods used in this paper required a vast data base. The selection of countries was subject to existence of a stock market with a stock index which would represent the stock market development. On the other hand it was subject to availability of a credible dataset of the selected indicators. In the final phase 20 countries were included into the analysis.

The stock market development of each country was gauged by the $\mathrm{MSCl}$ index. $\mathrm{MSCl}$ Inc. is a provider of investment decision support tools to investment institutions. This choice ensured comparable compilation of indexes for each country.

Macroeconomic indicators that significantly determine the value of a stock market index were selected based on economic theory. Based on the literature [13], [24] the following indicators were selected:

- gross domestic product,

- inflation,

- interests rate,

- rate of unemployment,

- value of export,

- value of import.

Time series data of the selected indicators were obtained from the OECD statistical database. Due to limited data availability only quarterly data from 1Q 2001 to 3Q 2011 were used. Some missing values had to be replaced with standard statistical procedures.

\section{Correlation Analysis}

To determine the degree of linear dependence within an analysis of relationship between two variables $\mathrm{x}$ and $\mathrm{y}$, correlation coefficient is often used. If the correlation coefficient is significantly non-zero, then the variables $\mathrm{x}$ and $\mathrm{y}$ are understood as correlated in a sense that it is an indication of a symmetric linear relationship between them [5]. Pearson's correlation coefficient $r$ is determined by the formula:

$$
r=\frac{n \sum x_{i} y_{i}-\sum x_{i} \sum y_{i}}{\sqrt{\left[n \sum x_{i}^{2}-\left(\sum x_{i}\right)^{2}\right]\left[n \sum y_{i}^{2}-\left(\sum y_{i}\right)^{2}\right]}} .
$$

\section{Factor Analysis}

Factor analysis is a multivariate statistical method that is used to reduce the number 
of initial variables, with no significant loss of information. On the basis of a smaller number of unknowns - a latent variable - explains the correlation structure of a group of manifest variables. It is based on the assumption that manifest variables are results of common causes, which are not explicitly known. The aim of factor analysis is to identify these underlying causes, quantify and interpret them. Figure 1 graphically depicts the principles of factor analysis. The original number of manifest variables is reduced to a smaller number of latent variables, with minimal loss of information.

\section{Factor Analysis (FA) Model}

Factor analysis model records the relationship between the vector of measured manifest variables $\mathbf{Y}=\left(\mathrm{Y}_{1}, \mathrm{Y}_{2}, \ldots . \mathrm{Y}_{\mathrm{n}}\right)$, and one or more latent variables $\mathbf{F}=\left(\mathrm{F}_{1}, \mathrm{~F}_{2}, \ldots . . \mathrm{F}_{\mathrm{m}}\right)$. Latent variables in this regard explain correlation $\mathbf{Y : ~} \mathbf{F} \rightarrow \mathbf{Y}$. But they are not known and need to be found and quantified. FA model using the equations can be written as follows:

$$
\begin{gathered}
Y_{1}=a_{11} F_{1}+a_{12} F_{2}+\cdots+a_{1 m} F_{m}+\varepsilon_{1}, \\
Y_{2}=a_{21} F_{1}+a_{22} F_{2}+\cdots+a_{1 m} F_{m}+\varepsilon_{2}, \\
\cdots \cdots \\
Y_{n}=a_{n 1} F_{1}+a_{n 2} F_{2}+\cdots+a_{1 n} F_{n}+\varepsilon_{n},
\end{gathered}
$$

Apart from the already mentioned manifest and latent variables, the model also includes the conversion coefficients $\left(a_{n m}\right)$ and errors of equation $\varepsilon$ [2]. Coefficients $a_{n m}$ are unknown model parameters, which are supposed to be estimated. They are also called factor coefficients or factor loadings and are equal to the value of the correlation coefficient between the latent and manifest variable. Parameter $\varepsilon$ is the residuum of the model, which is the part of the original data that is not explained by the latent variables $F$. It is assumed that this component is independent of factors, and its mean value is 0 . There will be always a greater or equal number of manifest variables than latent variables in FA model.

\section{Determining the Number of Factors}

The number of latent variables or factors can be also determined by several basic rules:

- using Kaiser's rule which determines the number of factors by the number of eigenvalues of the correlation matrix greater than 1 ,

- using the percentage of explained variability,

- using subjective judgment, i.e. based on interpretability, meaningfulness and usefulness of these factors [11].

\section{Fig. 1: Schematic model of factor analysis}

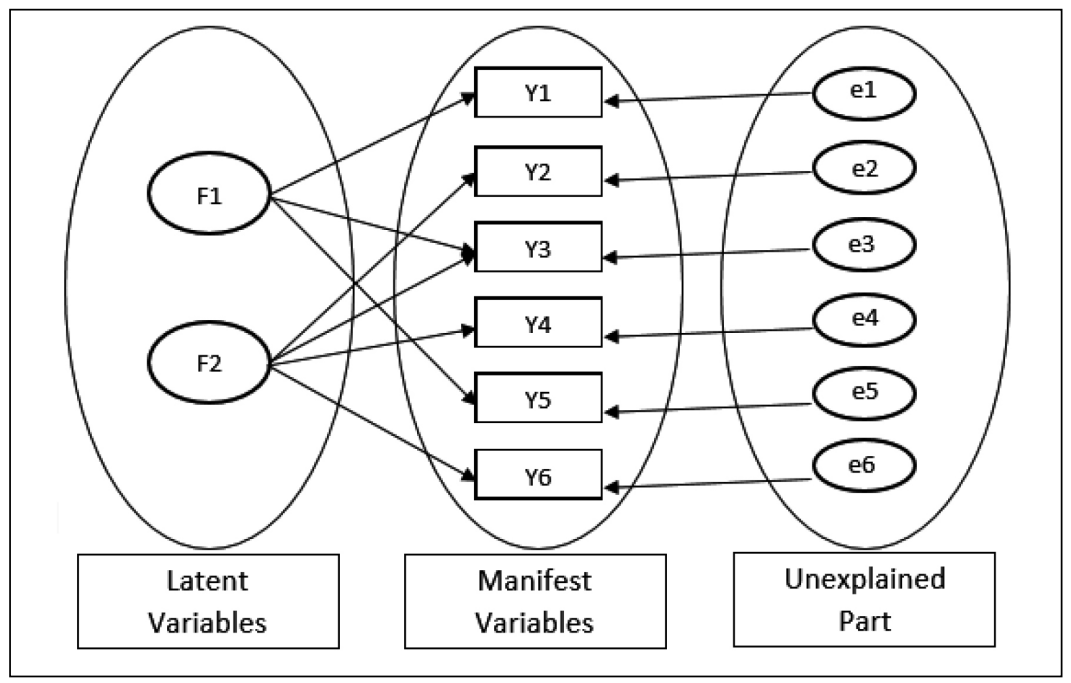

Source: own 


\section{Cluster Analysis}

According to Hebák [9] objects may be classified in two ways. These are either classification of objects by estimating values of the nominal dependent variable or grouping without using the explained variable. The second method is used by cluster analysis. This leads to beneficial results, especially in cases where objects naturally disintegrate into several classes.

The aim of cluster analysis is to create a situation where objects within a cluster are as similar as possible while objects from different clusters are similar as little as possible [9], [21]. Let us suppose a data matrix $X(n \times p$ type $)$, a set of partitions of $n$ objects into k clusters can be considered.

The result of hierarchical methods is creation of a hierarchy of groups of objects. These methods can be divided into agglomerative (successive clustering objects) and divisional methods (progressive distribution of a set of objects into subsets). To assess the degree of achievement of the objectives of cluster analysis, several criteria were suggested [9]. Criteria which resemble interpretation of multivariate analysis of variance are most used. It is (an) intra-cluster variation matrix:

$$
E=\sum_{h=1}^{k} \sum_{i=1}^{n_{h}}\left(x_{h i}-\bar{x}_{h}\right)\left(x_{h i} \bar{x}_{h}\right)^{T}
$$

and an inter-cluster variation matrix:

$$
B=\sum_{h=1}^{k} n_{h}\left(\bar{x}_{h}-\bar{x}\right)\left(\bar{x}_{h}-\bar{x}\right)^{T}
$$

Which in sum form a total variation matrix:

$$
T=\sum_{h=1}^{k} \sum_{i=1}^{n_{h}}\left(x_{h i}-\bar{x}\right)\left(x_{h i}-\bar{x}\right)^{T} .
$$

As many as possible distant compact groups are formed by reaching minimum of total sum of squared deviations of all (the) values from (the) respective cluster averages:

$$
G_{1}=s t E=\sum_{h=1}^{k} \sum_{i=1}^{n_{h}} \sum_{j=1}^{p}\left(x_{h i j}-\bar{x}_{h j}\right)^{2}
$$

Criterion $\mathrm{G}_{1}$ is called Ward's criterion.

\section{Measures of Distances and Similarities}

To determine the similarity between two objects, there is a large number of coefficients. Either measures of similarity or dissimilarity are used to examine for similarity. Řezanková [21] presents a broad list of similarity measures sorted by types of input data.

To express the relationship between two objects of quantitative data, measures of distance based on presentation of objects in space, which are represented by each variable, are used. The Euclidean distance is among the most used distances:

$$
D e\left(x_{i}, x_{j}\right)=\sqrt{\sum_{l=1}^{m}\left(x_{i l}-x_{j l}\right)^{2}},
$$

Manhattan distance (distance of city blocks), Chebishev distance and many other measures exist. [21].

\section{Similarity of Variables}

In the case of assessing the relationship between two objects characterized by values of quantitative variables one usually talks about distance. When assessing the relationship between two variables - one talks about dependence. Measures of intensity of mutual statistical dependencies are used as measures of similarity. As a base rate for this survey, Hebák [9] and Řezanková [21] indicate sample Pearson's correlation coefficient.

In the first step of creating clusters, two nearest objects connect at first pursuant to the distance. In the next steps, the formed clusters are considered to be objects and are subjected to clustering according to the same principles as the original objects [10]. For further clustering process the basis is a matrix of distances between each pair of objects. As similarity measure of clusters centroid linkage was used [9].

\section{Results}

Simple correlation coefficients were calculated between the value of the stock market index of the country and the values of all macroeconomic indicators. They reflect not only the strength of the linear relationship between the two variables, but also express the direction of this relationship. Calculated values of individual indicators meet the requirements based on economic theory. $\mathrm{R}$ correlation coefficients 


\begin{tabular}{l|r|r|r|r|r|r}
\multicolumn{1}{c|}{$\mathbf{r}$} & Inflation & Interest rate & $\begin{array}{c}\text { Unemployment } \\
\text { rate }\end{array}$ & GDP & Exports & Imports \\
\hline Australia & 0.230 & 0.192 & -0.808 & 0.829 & 0.749 & 0.839 \\
\hline Canada & 0.116 & -0.726 & -0.314 & 0.920 & 0.044 & 0.943 \\
\hline Czech Republic & 0.187 & -0.385 & -0.738 & 0.929 & 0.885 & 0.891 \\
\hline France & 0.171 & -0.169 & -0.147 & 0.772 & 0.793 & 0.717 \\
\hline Germany & 0.389 & -0.192 & -0.235 & 0.806 & 0.794 & 0.743 \\
\hline Greece & 0.058 & -0.488 & -0.643 & 0.616 & 0.788 & 0.777 \\
\hline Hungary & 0.033 & -0.281 & 0.393 & 0.871 & 0.712 & 0.777 \\
\hline Ireland & 0.492 & -0.583 & -0.740 & 0.249 & -0.096 & 0.265 \\
\hline Italy & 0.111 & -0.372 & -0.800 & 0.846 & 0.691 & 0.616 \\
\hline Japan & 0.313 & 0.735 & -0.808 & 0.792 & 0.691 & 0.739 \\
\hline Korea & 0.049 & -0.472 & -0.300 & 0.874 & 0.867 & 0.897 \\
\hline Mexico & -0.136 & -0.627 & 0.600 & 0.947 & 0.944 & 0.949 \\
\hline Netherlands & 0.011 & -0.066 & -0.045 & 0.618 & 0.595 & 0.587 \\
\hline Poland & 0.149 & -0.533 & -0.701 & 0.659 & 0.756 & 0.787 \\
\hline Portugal & 0.013 & -0.178 & 0.286 & 0.762 & 0.661 & 0.740 \\
\hline Spain & 0.059 & -0.308 & -0.024 & 0.866 & 0.729 & 0.907 \\
\hline Sweden & 0.222 & -0.567 & 0.274 & 0.871 & 0.880 & 0.857 \\
\hline Switzerland & 0.126 & -0.357 & 0.189 & 0.840 & 0.890 & 0.902 \\
\hline United Kingdom & 0.257 & 0.246 & -0.136 & 0.661 & 0.612 & 0.734 \\
\hline United States & 0.344 & 0.290 & -0.297 & 0.563 & 0.462 & 0.679 \\
\hline & & & & & & \\
\hline
\end{tabular}

expressing the relationship between the index and the various economic indicators are shown in table 1.

The actual value of the correlation coefficient corresponds to the strength of the relationship between the two variables. The closer the value of the correlation coefficients to the outer values of the interval $<-1 ; 1>$ is, the stronger the relationship between the two variables. It turns out that a significant determinant of the value of stock market index is especially gross domestic product. The positive values of correlation coefficients in column GDP confirm that growing gross domestic product results in growth of stock market index. The same impact on the values of the stock exchange indices is observed also in variables export and import, which are however already included in the aggregated
GDP (GDP is determined using the expenditure approach). Sensitivity of stock market indices to GDP is the result of changes in GDP, which is the best widely available measure of levels and productivity growth while also acting as a carefully timed pulse of the economy [22]. On the other hand, it is evident that the values of correlation coefficients between stock market indices and inflation oscillate between $0-0.3$, indicating that the linear relationship between these variables is very weak. Although the correlation coefficients are very low, values again correspond with economic theory. If the pace of price increase does not exceed the rate of growth of production, there is real economic growth. This increases total demand, the rise in prices increases profits raising incentives to expand production and hence additional 
demand for investment, which positively impacts capital markets [20].

Before performing a cluster analysis which reveals in which states the development of the main macroeconomic variables in relation to the stock market index were same or different, a factor analysis will be performed. Its aim is to reduce the number of original variables with minimal loss of information, as well as capture, by common factors, the effects of indicators operating in the same direction. Firstly, the assumptions for using factor analysis were verified using the Kaiser-Meyer-Olkin test and using the Bartlett test. The value of the $\mathrm{KMO}$ test based on a pairwise comparison of correlation coefficients yields the value 0.746 . This indicates that the input variables are correlated and are thus suitable for factor analysis. Bartlett's test also confirms suitability of the data for factor analysis.

The results of the factor analysis are summarized in table 2. Each line in the output corresponds to a single factor which was extracted by using the method of principal components. If one tried to explain $100 \%$ of the variability it would be necessary to work with a total of six factors, however, in this case the number of factors would be equal to the number of input variables.

In this analysis, the optimum number of factors is determined to be two factors. In the second column of table 2 the initial eigenvalues are given which corresponds to the percentage proportion of explained variability. The first factor therefore explains almost $52 \%$ of the variability, while the second factor always explains a lower amount of variability. In this case, the value is almost $20 \%$. Together, the two factors explain $72 \%$ of variability. By adding additional factors the percentage of explained variability increased, however, based on the recommendation of Kaiser's rule the optimal number of factors is just two. The right side of the table presents the percentage of variability assigned to each factor after rotation (Varimax method). The total percentage of explained variability is unchanged; there is only a change in the explained variability linked to a specific factor.

Table 3 shows the values of the factor loads. They are actually the simple correlation coefficients between the variables and the respective factors. For the purpose of clarity only correlation coefficients greater than 0.3 are shown.

It turns out that in terms of the values of correlation coefficients explained by a factor, each factor explains three variables. Variables GDP, Export and Import are bound to the first factor, while Inflation, Unemployment rate and Interests rate are bound to the second.

It means that only two variables, the factor scores that represent all six original macroeconomic indicators, enter the cluster analysis. Factor scores are estimated based on the inverse relationship between the original variables and factors. The distance between the profiles was calculated using Euclidean distances and linking of objects was done by using the centroid method. The process of

\section{Tab. 2: Results of factor analysis}

\begin{tabular}{c|r|r|r|r|r|r}
\multirow{2}{*}{ Component } & \multicolumn{3}{|c|}{ Initial Eigen values } & \multicolumn{2}{c}{ Rotation Sums of Squared Loadings } \\
\cline { 2 - 7 } & Total & \% of Variance & $\begin{array}{c}\text { Cumulative } \\
\%\end{array}$ & Total & \% of Variance & $\begin{array}{c}\text { Cumulative } \\
\%\end{array}$ \\
\hline $\mathbf{1}$ & 3.116 & 51.926 & 51.926 & 2.686 & 44.762 & 44.762 \\
\hline $\mathbf{2}$ & 1.196 & 19.930 & 71.856 & 1.626 & 27.094 & 71.856 \\
\hline $\mathbf{3}$ & 0.733 & 12.209 & 84.065 & & & \\
\hline $\mathbf{4}$ & 0.456 & 7.596 & 91.661 & & & \\
\hline $\mathbf{5}$ & 0.358 & 5.971 & 97.632 & & & \\
\hline $\mathbf{6}$ & 0.142 & 2.368 & 100.000 & & & \\
\hline
\end{tabular}




\begin{tabular}{l|c|c}
\multirow{2}{*}{} & \multicolumn{2}{|c}{ Component } \\
\cline { 2 - 3 } & $\mathbf{1}$ & $\mathbf{2}$ \\
\hline Inflation & -0.557 & 0.640 \\
\hline Interests rate & & 0.866 \\
\hline Unemployment rate & 0.356 & -0.605 \\
\hline GDP & 0.879 & \\
\hline Exports & 0.843 & \\
\hline Imports & 0.864 & \\
\hline
\end{tabular}

Source: SPSS, own calculations

Tab. 4: Results of cluster analysis

\begin{tabular}{c|c|c|c|c|c|c}
\multirow{2}{*}{ Stage } & \multicolumn{2}{|c|}{ Cluster Combined } & \multirow{2}{*}{ Coefficients } & \multicolumn{2}{c}{ Stage Cluster First Appears } & \multirow{2}{*}{ Next Stage } \\
\cline { 2 - 3 } & Cluster 1 & Cluster 2 & & Cluster 1 & Cluster 2 & \\
\hline $\mathbf{1}$ & 11 & 18 & 0.001 & 0 & 0 & 2 \\
\hline $\mathbf{2}$ & 11 & 16 & 0.007 & 1 & 0 & 9 \\
\hline $\mathbf{3}$ & 6 & 14 & 0.027 & 0 & 0 & 6 \\
\hline $\mathbf{4}$ & 7 & 17 & 0.031 & 0 & 0 & 8 \\
\hline $\mathbf{5}$ & 5 & 19 & 0.079 & 0 & 0 & 11 \\
\hline $\mathbf{6}$ & 6 & 13 & 0.095 & 3 & 0 & 10 \\
\hline $\mathbf{7}$ & 4 & 9 & 0.113 & 0 & 0 & 10 \\
\hline $\mathbf{8}$ & 7 & 15 & 0.115 & 4 & 0 & 9 \\
\hline $\mathbf{9}$ & 7 & 11 & 0.203 & 8 & 2 & 12 \\
\hline $\mathbf{1 0}$ & 4 & 6 & 0.251 & 7 & 6 & 12 \\
\hline $\mathbf{1 1}$ & 5 & 20 & 0.568 & 5 & 0 & 14 \\
\hline $\mathbf{1 2}$ & 4 & 7 & 0.758 & 10 & 9 & 13 \\
\hline $\mathbf{1 3}$ & 3 & 4 & 0.944 & 0 & 12 & 15 \\
\hline $\mathbf{1 4}$ & 1 & 5 & 0.970 & 0 & 11 & 16 \\
\hline $\mathbf{1 5}$ & 2 & 3 & 1.663 & 0 & 13 & 16 \\
\hline $\mathbf{1 6}$ & 1 & 2 & 2.110 & 14 & 15 & 17 \\
\hline $\mathbf{1 7}$ & 1 & 12 & 4.045 & 16 & 0 & 18 \\
\hline $\mathbf{1 8}$ & 1 & 10 & 7.354 & 17 & 0 & 19 \\
\hline $\mathbf{1 9}$ & 1 & 8 & 15.061 & 18 & 0 & 0 \\
\hline & & & & & & 0 \\
\hline
\end{tabular}


aggregation of individual countries is shown in table 4 . In the first stage, clustering merged Korea and Switzerland into a single cluster. Proximity between the two countries amounts to only 0.001 . Surprisingly, in the second stage Spain was added to the same cluster, whose distance from Korea was only 0.007 . On the contrary, countries which were very different in this context were Ireland and Japan which joined in the clustering at the very end. Their proximity to the nearest cluster center was 15.061 and 7.354 respectively. The right side of table 4 suggests at which level the common cluster emerged and where the next step in clustering appears.

The whole process of clustering is shown in figure 2 (Dendrogram). The main cluster consists of twelve states, which are later on joined by Canada. Another compact cluster includes Germany, United Kingdom, USA and Australia. Orphaned remained Mexico, Japan and Ireland. Extraordinary position of the Czech Republic within the main cluster may be caused by relatively high value of the correlation coefficient $(r=0.929)$ between GDP and a value of the stock market index.

After re-examination of the input data for factor and cluster analysis the reasons were identified that led to that allocation of the individual states to the particular clusters. Late integration of Canada into the main cluster was probably due to the high value of the correlation coefficient of the interest rate. What is surprising is the relatively low value of $r$ for exports and imports. The main cluster consists of countries whose stock market index most correlated with GDP, while the average $r=0.803$ and lowest $r$ was measured in Greece (0.616). Also noteworthy is the average $r$ for the interest rate $(-0.377)$.

The second cluster (Germany, United Kingdom, USA and Australia), is characterized by the fact, that interest rate in large and developed economies is not as influential as

\section{Fig. 2: Results of cluster analysis - Dendrogram}

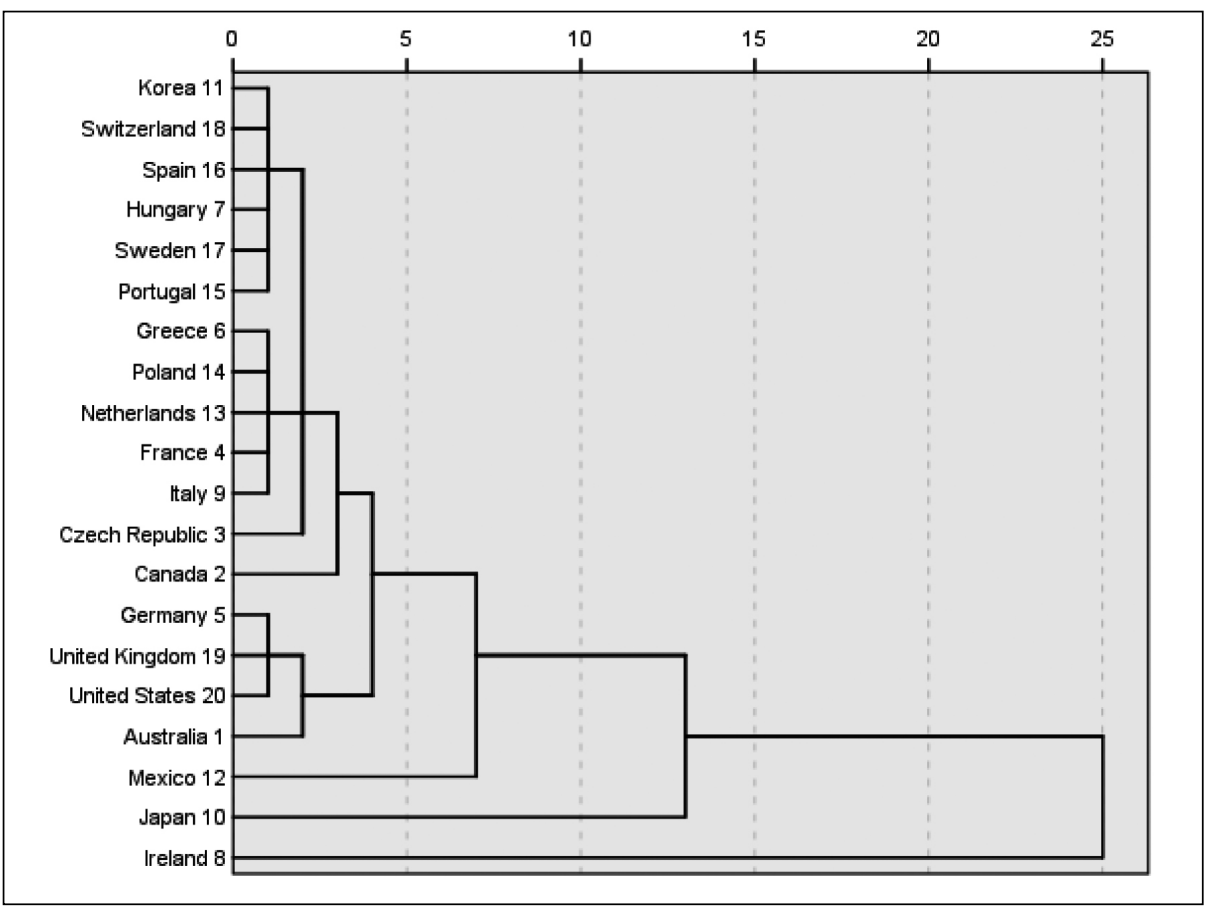

Source: SPSS, own calculations 
in other countries (mean $r=0.134$ ). Relatively strong remained the relationship between GDP and stock exchange index (mean $r=0.715$ ) with unemployment (average $r=-0.369$ ) and inflation (average $r=0.305$ ) getting in the foreground. Mexico did not join any cluster because of the high positive value $r$ for unemployment (0.6). As the only country, Canada had a positive $r$ with inflation. Japan is a separate unit due to the high positive $r$ for interest rate $(0.735)$. Specific situation occurred in Ireland where the correlation coefficient for GDP was only 0.249 and thus it considerably differs from all other countries.

\section{Discussion}

The result of the correlation analysis shows that the relationship between basic macroeconomic indicators and stock market index values of individual countries is not always fully in line with the expected economic theory. This contradiction was most evident in case of inflation, which has according to the results in our analysis in most countries positive relationship, whereas Kim [14] concluded in his study that this relationship is negative. Almost every economic indicator always manifests itself in contradiction with the assumptions at least for one country. The only exception is indicators of GDP and indicators of Imports, for which the correlation with the stock market index of the country is always positive, indicating a positive relationship. A positive impact of economic development, represented by value of GDP, on stock market indices was also described for instance by Kim [14], Gjerde and Satta [7] and Binswanger [3]. Nevertheless, the strength of this relationship particularly between GDP and stock market indices fluctuates considerably, reaching different levels in individual countries. Compliance with economic theory and also with other papers (e.g. [1]) was confirmed in relation to the interest rate, where there is a positive relationship with market stock index.

In contrast, the indicator of Imports shows both the strongest linear relationship, which is on average the highest values, and the smallest variability. It is clear that growth of imports leads to significant increases in values stock exchange indices. This can be explained by increasing attractiveness of the country to investors, increasing purchasing power of the population and basically by overall economic growth. The very strong influence of import and export was also confirmed by study of Abdullah and Hayworth [1]. They did not work directly with these two variables but used trade deficit, which is derived from those variables.

The results of the cluster analysis brought on one hand expectable results, on the other many surprises as well. Large countries, both in terms of land area, and particularly in terms of economic performance, such as the United Kingdom, the United States, Australia and Germany were included in the same cluster. The impact of the economic indicators on the stock market indices showed common features that were so different from the other countries that grouping with the other clusters occurred only at the very end of the analysis.

In contrast, the results of clustering in the case of small countries are interpretatively not too clear. There appeared states such as Sweden and Switzerland, along with countries such as Portugal and Spain in joint clusters. It means countries significantly affected by the economic crisis, still in poor economic conditions and countries that in contrast were affected by the crisis less and economically are still doing very well. The inconsistency in the results confirmed the composition of the next cluster, which grouped together the Netherlands, France as well as Greece and Poland.

It turns out that the impact of macroeconomic indicators is related not only to the maturity of the economy and its current condition, but also to its economic power, that is the size of the economy. Larger economies show common behavior in terms of the impact of macroeconomic indicators on stock market index values, whereas smaller economies provide more ambiguous results. This situation could be caused mainly due to a lower resistance of smaller countries against the effects and the development of the stronger economies.

Involvement of the Czech Republic in later phases of the clustering process may be explained by the higher value of the correlation coefficient between GDP and the market index. Its value was the second highest among all countries, after Mexico. Unusually high value of this coefficient is apparently a reason why Czech Republic has an extraordinary position within the main cluster but also why Mexico joined to the clustering process almost at the very end. Although this relationship is in 
accordance with economic theory, higher value of this coefficient is still the source of some differences.

\section{Conclusion}

Due to using a large dataset it was possible to carry out a major macroeconomic research. Already the table of correlation coefficients in table 1 forms a good basis for assessing the relationships between the variables at the macroeconomic level. The direction of the relationship between the selected macroeconomic indicators and the stock market indices in most cases corresponds to the general economic theory. It was also found that the strength of the relationship between the indicators and the stock exchange index differs between countries. This is due to a different state of the individual economies, as well as their openness, sensitivity of their stock market indices to the development of the economy or the confidence of investors in these countries. In three cases there were even revealed significant deviations from generally applicable laws. Specific characteristics of economic correlations for Mexico, Japan and Ireland were described. The identified traits would require deeper economic analysis of these countries.

It should be pointed out that the final clusters are not groups of countries with similar development in macroeconomic indicators, but of countries in which these indicators have a similar effect on the value of the stock market index in the country. After exclusion of Mexico, Japan and Ireland, a group of seventeen remaining countries is naturally divided into two clusters. The main cluster comprises 13 countries, which are composed of a variety of European and non-European economies. In the second cluster there are Germany, USA, UK and Australia. In these countries characterized by large, developed economies a significantly weaker dependence between stock exchange index and interest rate was identified in comparison with the main cluster. It shows that interest rate substantially affects behavior of investors, and that they are probably more resistant to time preference [12]. The main cluster is formed, in terms of performance of national economies, by a heterogeneous group of countries. Except Ireland and the large states of Germany and United Kingdom, all remaining European countries were classified into this cluster. This confirms that although the national economies are unequally powerful, the effects of macroeconomic indicators on stock market index values are similar, albeit with varying intensity.

\section{References}

[1] ABDULLAH, D.A. and HAYWORTH, S.C. Macroeconometrics of Stock Price Fluctuations. Quarterly Journal of Business and Economics. 1993, Vol. 32, pp. 50-67. ISSN 0747-5535.

[2] ANDĚL, J. Statistické metody. Praha: Matfyzpress, 1993. ISBN 80-86732-08-8.

[3] BINSWANGER, M. Stock Returns and Real Activity: Is There Still a Connection? Applied Financial Economics. 2000, Vol. 10, Iss. 4, pp. 379-387. ISSN 0960-3107. DOI: $10.1080 / 09603100050031507$.

[4] BULMASH, S.B. and TRIVOLI, G.W. TimeLagged Interactions between Stock-Prices and Selected Economic Variables - Are StockPrices Related to Economic Cycles? Journal of Portfolio Management. 1991, Vol. 17, Iss. 4, pp. 61-67. ISSN 0095-4918. DOI: 10.3905/ jpm.1991.409351.

[5] CIPRA, T. Finanční ekonometrie. Praha: Ekopress, 2008. ISBN 978-80-86929-43-9.

[6] CHENG, A.C.S. The UK Stock Market and Economic Factors: A New Approach. Journal of Business Finance \& Accounting. 1995, Vol. 22, Iss. 1, pp. 129-142. DOI: 10.1111/j. ISSN 14685957. ISSN 1468-5957.

[7] GJERDE, O. and SAETTEM, F. Casual Relations among Stock Returns and Macroeconomic Variables in a Small, Open Economy. Journal of International Finance Markets Institutions and Money. 1999, Vol. 9, Iss. 1, pp. 61-74. ISSN 1042-4431. DOI: 10.1016/S1042-4431(98)00036-5.

[8] GOH, J.C., et al. Can US Economic Variables Predict the Chinese Stock Market? Pacific-Basin Finance Journal. 2013, Vol. 22, pp. 69-87. ISSN 0927-538X. DOI: 10.1016/j.pacfin.2012.10.002.

[9] HEBÁK, P., et al. Vícerozměrné statistické metody (3). Praha: Informatorium, 2007. ISBN 978-80-7333-001-9.

[10] HENDL, J. Přehled statistických metod zpracováni dat. 2nd ed. Praha: Portál, 2006. ISBN 80-7467-124-9.

[11] HINDLS, R., HRONOVÁ, S. and SEGER, J. Statistika pro ekonomy. Praha: Professional Publishing, 2002. ISBN 80-86419-30-4.

[12] HOLMAN, R. Ekonomie. 5th ed. Praha: C. H. Beck, 2011. ISBN 978-80-7400-006-5. 
[13] JíLEK, J. Akciové trhy a investování. 1st ed. Praha: GRADA Publishing, 2009. ISBN 978-80-247-2963-3.

[14] KIM, K. Dollar Exchange Rate and Stock Price: Evidence from Multivariate Cointegration and Error Correction Model. Review of Financial Economics. 2003, Vol. 12, Iss. 3, pp. 301313. ISSN 1058-3300. DOI: 10.1016/S10583300(03)00026-0.

[15] KRALIK, L.I. Relationship between Macroeconomic Variables and Stock Market Returns on Bucharest Stock Exchange. Metalurgia International. 2012, Vol. 17, Iss. 8, pp. 127-132. ISSN 1582-2214.

[16] MUKHERJEE, T., NAKA, A. Dynamic Relations between Macroeconomic Variables and the Japanese Stock Market: An Application of a Vector Error Correction Model. Journal of Financial Research. 1995, Vol. 18, Iss. 2, pp. 223-237. ISSN 1475-6803. DOI: 10.1111/ j.1475-6803.1995.tb00563.x

[17] OSKENBAYEV, Y., YILMAZ, M. and CHAGIROV, D. The impact of Macroeconomic Indicators on Stock Exchange Performance in Kazakhstan. African Journal of Business Management. 2011, Vol. 5, Iss. 7, pp. 2985-2991. ISSN 1993-8233. DOI: 10.5897/AJBM10.1480.

[18] PANETTA, F. The Stability of the Relation between the Stock Market and Macroeconomic Forces. Economic Notes: Review of Banking, Finance and Monetary Economics. 2002, Vol. 31 , Iss. 3, pp. 417-450. ISSN 1468-0300. DOI: 10.1111/1468-0300.00093.

[19] PILINKUS, D. and BOGUSLAUSKAS, V. The Short-Run Relationship between Stock
Market Prices and Macroeconomic Variables in Lithuania: An Application of the Impulse Response Function. Inzinerine EkonomikaEngineering Economics. 2009, Iss. 5, pp. 2633. ISSN 1392-2785.

[20] ROUBAL K. Ekonomická encyklopedie. Praha: Svoboda, 1972. ISBN 25-103-72.

[21] ŘEZANKOVÁ, H., et al. Shluková analýza dat. Příbram: Professional publishing, 2009. ISBN 978-80-86946-81-8.

[22] SAMUELSON, P.A. and NORDHAUS, W.D. Ekonomie. Praha: Svoboda, 1995. ISBN 80-205-0494-X.

[23] SNIESKA, V., LASKIENE, D. and PEKARSKIENE, I. Stock Returns and the Macroeconomic Environment: The Case of the Vilnius Stock Exchange. Transformations in Business \& Economics. 2008, Vol. 7, Iss. 2, pp. 115-129. ISSN 1648-4460.

[24] VESELÁ, J. Investování na kapitálových trzích. Praha: ASPI, 2007. ISBN 978-80-7357297-6.

Ing. Rudolf Plachý, Ph.D. Czech University of Life Sciences in Prague Faculty of Economics and Management Department of Statistics plachyr@pef.czu.cz

Ing. Tomáš Rašovec, Ph.D. Czech University of Life Sciences in Prague Faculty of Economics and Management Department of Statistics rasovec@pef.czu.cz 


\section{Abstract}

\section{IMPACT OF ECONOMIC INDICATORS ON DEVELOPMENT OF CAPITAL MARKET}

\section{Rudolf Plachý, Tomáš Rašovec}

The capital market is one of the most important elements of any healthy, well-functioning economy. The volume and value of executed capital market transactions are affected not only by the number of issuers and investor's willingness to buy, but also by economic development in the broadest sense. This article discusses the relationship between macroeconomic indicators and development of stock market index in different countries. It assesses the direction and intensity of relationships between macroeconomic indicators and stock market index and explains possible causes of these conditions. Analysis of the relationship is carried out in different countries with different levels of economic development, both in Europe and overseas. Emphasis was put on the selection of those countries, which were significantly affected by the economic recession. The indicators that affect value of stock market index were selected based on economic theory. Among them belong: gross domestic product, inflation, interest rate, export, and import and unemployment rate. After determining the degree of dependence between macroeconomic indicators and value of stock market index, countries were grouped together in clusters. Clustering was therefore not conducted on the basis of the values of macroeconomic indicators of a country, but on the basis of these indicators having a similar effect on the value of the stock market index. Before cluster analysis, input matrix of variables was subjected to factor analysis to reduce the original number of variables.

Key Words: Capital market index, macroeconomic indicators, factor analysis, cluster analysis.

JEL Classification: C38.

DOI: 10.15240/tul/001/2015-3-010 